\title{
Mental health and depression among school going adolescents: excerpts from a school based study of Nadia district, West Bengal
}

\author{
Gandhari Basu', Sujata Biswas² \\ ${ }^{1}$ Assistant Professor, Department of Community Medicine, ${ }^{2}$ Assistant Professor, Department of Physiology, College of \\ Medicine \& JNM Hospital, West Bengal University of Health Sciences, Kalyani, West Bengal, India
}

\section{A B S T R A C T}

Background: Adolescence is the gateway to health promotion and marked as the transition period between childhood and adulthood. They suffer from various psychosocial problems at any point of their life. Depression during adolescence is considered as an important public health emergency. Aims and Objectives: To assess the presence of some mental health symptoms by Beck's Depression Inventory (BDI) among school going adolescents and also to find out the prevalence of depression along with associated factors. Materials and Methods: A crosssectional, descriptive epidemiological study was conducted among adolescents of class VII to IX of an English medium school of Kalyani in Nadia district between July and August, 2016. Information on socio demographic variables along with responses on the questions related to various aspects of mental health was gathered by validated BDI and Global school health survey questionnaire. Depression was classified based on the scores obtained and a scale was used. Results: A total of 167 adolescents were assessed, mean age of 13.63 years with more boys (110). Mental health analysis revealed nine attempted suicide cases. Nearly half of the pupil reported of punishment feelings (71) and self-criticism (68). The prevalence of overall depression was $34.2 \%$, mild one topped the list. Level of depression was significantly more in higher age group, class VII and among those adolescents who did not stay with their parents $(\mathrm{P}<.01)$. Conclusion: The present study provides a composite scenario of mental health status and depression among adolescents. The findings reveal that depression is gradually increasing in respondents. This study also demonstrated the need for secondary prevention and raises deep concern. School based training programme and quarterly counselling under psychiatrist's guidance in a holistic approach may manage the problem to a great extent.

Key words: Adolescents, Mental health, Beck's depression inventory, Global school health survey, Depression
Access this article online

Website:

http://nepjol.info/index.php/AJMS

DOI: 10.3126/ajms.v8i5.17499

E-ISSN: 2091-0576

P-ISSN: 2467-9100

\section{INTRODUCTION}

WHO identifies adolescence as the period in human growth and development that occurs after childhood and before adulthood, from ages 10 to19. It represents one of the critical transitions in the life span and is characterized by a tremendous pace in growth and change that is second only to that of infancy. The process of adolescence is a period of preparation for adulthood. ${ }^{1}$ The world is home to 1.2 billion individuals aged $10-19$ years.
Adolescents aged between 10 to 19 years account for more than one-fifth of the world's population. Presently, 1.2 billion adolescents make up 16 per cent of the world's population. The proportion of adolescents peaked in 1980 but now on the decline in every part globally, a trend expected to continue through 2050. The absolute number of adolescent is likely to increase during that same period. More than half of all adolescents live in Asia. South Asia is home to nearly 340 million adolescents. In India, this age group covers $21.4 \%$ of the total population. Globally, 
most of them are protected under the Convention on the Rights of the Child. Despite this, their needs and vulnerabilities often remain unnoticed. They lack the basic services as per their specific needs. The national programs mainly focus on newborns, under-fives. Adolescents are not reached by programs for adults., ${ }^{2,3}$ Mental well-being is the pillar behind happy and confident adolescents. Generally for ages, it was perceived that depression, anxiety, stress are not a matter of concern among adolescents. "Moody" or "difficult" was the term to describe those with depression. But now it is really shocking to know that up to $20 \%$ of them suffer from various disabling mental illnesses including depression. The disorders related to depression are considered as priority problems of adolescents as a result of increase in prevalence and other health related complications (World Health Organization). ${ }^{4}$ The implications are reflected in form of suicide, substance abuse, eating problems, stealing, school dropout, addiction, obesity and many more Mental health problems creates socioeconomic burden by contributing in development of more disabling conditions later in life. Meanwhile in India, adolescents are in constant pressure as a result of rat race in school examinations. This academic stress contributes distress in some manifested in form of psychological and behavioral problems. In India, more than six children per day committed suicide because of failure in examinations in year 2011 only. ${ }^{5}$ Depression among this age group has impact on teen's socialization, academic performance, family relations. They are at risk of addiction, antisocial behaviors and also psychosocial impairment. Of course, the most devastating outcome of concern for adolescent depression is suicide, the third leading cause of death among older adolescents (Centre for Diseases Control, Atlanta). Still there is lack of perfect depression screening/assessment tool, but a number of depression assessment instruments do have adequate psychometric properties for assessing depression. The prevalence of depression and stress varies between $15 \%$ to $40 \%$ among Indian adolescents as per different studies. ${ }^{6-9}$ Therefore, the present study was conducted to find out the current status of mental health, prevalence and correlates of depression cum level of mood among school going adolescents.

\section{MATERIALS AND METHODS}

This current research was undertaken in an English medium school, situated in an important town Kalyani, of Nadia district, West Bengal. Kalyani is the sub-divisional headquarter of Nadia district, West Bengal. It was named by Dr. Bidhan Chandra Roy, Ex Chief Minister of West Bengal and act as an alternative to the city of Kolkata, from which it is about $50 \mathrm{~km}$ away. There are 20 wards with a total population of $100,575 .{ }^{10}$ There are 19 districts in West Bengal. By purposive sampling, Nadia district was chosen. In Nadia district, there are four subdivisions, Krishna Nagar, Kalyani, Tehatta and Ranaghat. Kalyani sub-division is selected by convenient sampling. Under Kalyani subdivision, 3 municipalities (Kalyani, Gayeshpur and Chakdah) represent urban area. Kalyani municipality is selected by simple random sampling. ${ }^{11}$ There are six high schools under Kalyani Municipality, and out of these, an English medium school was selected as per convenience. ${ }^{12}$ The adolescents who gave written consent after knowing objectives and not suffering from any diagnosed mental problems were allowed to participate. The sample size was calculated based on a study done by Nimal Verma, Meeta Jain and Pritam Roy among adolescents of Raipur city. ${ }^{13}$ Considering the prevalence of mild depression $40.49 \%$ in the reference study, with $8 \%$ relative precision, the sample size was calculated to be 150 using the formula of $4 \mathrm{pq} / 1^{2}$. After adding the non-response rate of $10 \%$, the final sample size was 165 but a total of 167 students took part. After getting necessary clearance from the institutional ethics committee, the head master of the selected school was met and his verbal consent was obtained after explaining the topic and the objectives in details. For getting the required sample size, adolescents of one section of each class from VII to IX, present on the survey day and fulfilling inclusion criterion, were included in the study. In the situation, where there is only one section in per class, that single section will represent the whole class. Finally, 167 participated in the study. Pre designed, semi-structured, self- administered proforma was used for collecting data on socio economic and demographic attributes, academic performance and mental health status. One day was reserved for each section. Students were given a brief lecture about the purpose of the study. The students were distributed a proforma consisting of socio-demographic aspects, some questions from Global school health survey (GSHS) and Becks Depression Inventory (BDI). From GSHS, four questions on aspects of mental health and four questions based on knowledge and source of information were included in this study. In 2001, World health organization in collaboration with some of world's top agencies and with technical assistance from the US Centers for Disease Control and Prevention (CDC), initiated development of the Global School-based Student Health Survey. The GSHS is a school-based survey conducted primarily among students aged 13 to 17 years. It measures risk behaviors and protective factors related to the leading causes of mortality and morbidity among youth and adults. ${ }^{14}$ Aaron Beck, a psychiatrist and professor emeritus at the University of Pennsylvania, developed the Beck Depression Inventory (BDI), which was originally published in 1961. The BDI was revised in 1978 as the 
BDI-1 and again in 1996 as the BDI-II. The most recent version of the BDI, the BDI-II, has 21 items with four multiple-choice responses. Each item measures a specific symptom of depression. A scale was used for classifying depression. The respondents scored between 1 and 10 were considered normal, between 11 and 16 had mild mood disturbance, 17 and 20 were considered to have borderline clinical depression, whereas scores ranging from 21 to 30 and 31 to 40 indicative of moderate and severe depression respectively. Extreme depression was indicated by the score above 40 . This inventory is a series of 21 questions that has been developed to measure the intensity and severity of depression in subjects. ${ }^{15,16}$ They were asked to fill up the proforma within 30 minutes with the assurance of anonymity and strict confidentiality of information gathered.

\section{Ethics}

The present study proposal was first presented before scientific review committee of the institution. After getting approval from the governing body, as per their directive, the modified research was again sent to Institutional Ethics Committee (IEC). The final permission was given by IEC to conduct the study.

\section{Statistics}

Results were analyzed using licensed statistical software (SPSS 22.0). Some of the responses were coded and analyzed. The analysis of BDI was based on the scores obtained For descriptive statistics, mean, median, range, standard deviation, proportion was used. Confidence interval, Odds ratio, Yates corrected chi square value was calculated for determining any association of statistical importance between depression and other related variables. All adolescents who scored for mild, moderate and severe depression formed the 'depression group' and others were in normal group. These two groups were used for chi square analysis. STATCALC Epi Info version 6.0 was used for calculating the association statistics ( $P$ value of $<0.05$ will be considered significant).

\section{RESULTS}

The present study had a total of 167 adolescents. Majority $(95.6 \%)$ were aged between 13 to 15 years with more number of boys (110). The average age was 13.63 years with a SD of 0.85 . There were 95 adolescents aged 13 years. The absolute number of respondents was 60,57 and 50 respectively in one section (under study) of class VII, VIII and IX respectively. The representation of nuclear family was more $(65.5 \%)$. Social classification was done as per modified Prasad's scale, 2016 taking into account All India Average Consumer Price Index (AICPI) of 267 for the base year 2016. Every two out of three students came from upper socio economic class as per modified Prasad'sscale, 2016. ${ }^{17}$ Among all only parents of two participants were illiterate. One hundred eleven (111) mothers and 130 fathers were educated up to higher secondary or more. Fathers were mainly in service $(40.1 \%)$ and business $(42.5 \%)$ whereas mothers were mostly homemakers (150). Most of the students were staying with their parents (155), six with mother, two with father and one in hostel. (Table 1)

It had been observed that nine (9) students even attempted suicide in their past which indicated the present scenario of increase level of stress among this age group. After analyzing the responses on the questions under GSHS, it was noticed that majority were never or rarely worried so much about something that would ignite the desire to have alcohol (160) and causing loss of appetite (123). In contrast, the response to the question of having hard time staying focused on homework or other things to do was quite striking. Thirty eight students replied that they had found it hard most of the times and 57 seemed to have hard time sometimes. No class was ever arranged in the school for stress handling, anger management and suicide prevention.

In Table 2, further detailed analysis of the items of BDI had shown that the feeling of pessimism and past failure was least among them, 5.4\% and 6.6\% only. The feeling of sadness was also less compared to other items, only in 20 students. Punishment feelings and self-criticism topped the list, 71 and 68 students reported respectively. Thirty seven students were not satisfied with own, nearly one in every five were indecisive, fifty seven felt like crying most the times. One third of the respondents felt guilty and had lost interest at most of the times. Depression was

\begin{tabular}{lc}
$\begin{array}{l}\text { Table 1: Respondent's background } \\
\text { characteristics (N=167) }\end{array}$ \\
\hline Variables & Frequency (\%) \\
\hline Age group (years) & \\
$13-15$ & $159(95.6)$ \\
$16-17$ & $8(4.8)$ \\
Sex & $110(65.9)$ \\
Male & $57(34.1)$ \\
Female & \\
Social class (modified Prasad's SES, 2016) & $111(66.5)$ \\
Class I & $36(21.6)$ \\
Class II & $11(6.6)$ \\
Class III & $9(5.4)$ \\
Class IV & \\
Relationship of parents & $162(97.0)$ \\
Staying together & $5(3.0)$ \\
Divorced/separated & \\
Academic performance in last exam & $20(12.0)$ \\
$>90 \%$ & $91(54.8)$ \\
$75-90 \%$ & $44(26.5)$ \\
$60-74 \%$ & $12(7.2)$ \\
$<60 \%$ & \\
\hline
\end{tabular}


noted among $34.2 \%$ (57) of adolescents, one in every three precise to say.

The present study had attempted to find the factors associated with presence of depression. The prevalence of depression along with chances of association were noted more among girls $(38.6 \%)$, students belonging to nuclear family $(34.9 \%)$ and scored less than $75 \%$ in last examination $(35.7 \%)$, but the association was insignificant. Less the literacy rate of parents, more prevalence of depression among their child. Depression is remarkably higher among those students who did not live with their parents.

\begin{tabular}{|c|c|c|}
\hline \multirow[t]{2}{*}{ Variables } & \multicolumn{2}{|c|}{ Responses (frequency, \%) } \\
\hline & Absent & Most of time/always \\
\hline Punishment feelings & $96(57.5)$ & $71(43.5)$ \\
\hline Self-criticism & 99 (59.3) & $68(41.7)$ \\
\hline Loss of pleasure & $104(62.3)$ & $61(37.7)$ \\
\hline Irritability & 105 (62.9) & $62(37.1)$ \\
\hline Guilty feelings & $109(65.3)$ & $58(34.7)$ \\
\hline Crying & $110(65.8)$ & $57(34.2)$ \\
\hline Loss of interest & $110(65.8)$ & $57(34.2)$ \\
\hline Loss of energy & $112(67.1)$ & $55(32.9)$ \\
\hline Suicidal thoughts & $117(70.1)$ & $50(29.9)$ \\
\hline Tiredness & $120(71.9)$ & $47(28.1)$ \\
\hline Changes in weight & 120 (71.9) & $47(28.1)$ \\
\hline Concern in own health & $120(71.9)$ & $47(28.1)$ \\
\hline Changes in appetite & $121(72.5)$ & $46(27.5)$ \\
\hline Worthlessness & $127(76.0)$ & $40(24.0)$ \\
\hline Change in sleep pattern & $127(76.0)$ & $40(24.0)$ \\
\hline $\begin{array}{l}\text { Level of mood/ } \\
\text { depression }\end{array}$ & \multicolumn{2}{|c|}{ Frequency (\%) } \\
\hline $\begin{array}{l}\text { Normal/Borderline } \\
\text { mood disturbance }\end{array}$ & \multicolumn{2}{|r|}{$110(65.9)$} \\
\hline Mild depression & \multicolumn{2}{|r|}{$40(24.0)$} \\
\hline Moderate depression & \multicolumn{2}{|r|}{$13(7.8)$} \\
\hline Severe depression & \multicolumn{2}{|r|}{$4(2.4)$} \\
\hline
\end{tabular}

Higher age group (16-17 years), pattern of stay and the present class was associated with presence of depression and this association was highly significant at $\mathrm{P}<0.01$ and 95\% Confidence interval. (Table 3) The attained score of depression was seen to be more significantly (P.002, $\mathrm{OR}=3.14,95 \% \mathrm{CI}=1.57-2.21$ ), among adolescents who had been so worried that they could not eat or did not feel hunger in last one year at sometimes or most of times. The respondents who did not feel to take alcohol or drugs due to worry in last 12 months had also suffered from depression (33.4\%). The proportion is $100 \%$ in those who always felt the desire. Similar proportion of depression was noticed in those who found it hard to concentrate mostly or always and who did not find it hard ever or rarely $(32.1 \%$ vs. $36.1 \%)$.

\section{DISCUSSION}

Depression is considered as one of the most common, important and ignorant public health problem among adolescents in recent times. The profound adverse effect on their physical and mental health can't be ignored. In present study, a total of 167 adolescents participated. One hundred and fifty nine students belong to $13-15$ years, average age of 13.63 years, and nearly equal representation from each class under study. Most of them lived in nuclear family (65.5\%). Most were Hindu. Two-thirds of students were from upper social class. The study done among adolescent girls of Uttar Pradesh found nearly similar results. In their study, the mean age was 14.3years, almost half (55.6\%) under were in age group 10 - 13 years. Majority (67.2\%) came from nuclear families, were Hindu. But in their research, two-third of adolescents belonged to upper lower and lower socio -economic status and this might be due to the fact our study school was an English medium school

Table 3: Association of depression with related variables

\begin{tabular}{|c|c|c|c|}
\hline \multirow[t]{2}{*}{ Socio demographic variables } & \multicolumn{2}{|c|}{ Level of depression } & \multirow[t]{2}{*}{ Statistics } \\
\hline & $\begin{array}{l}\text { No depression } \\
\text { (number) }\end{array}$ & $\begin{array}{l}\text { Depression present } \\
\text { (number, percentage) }\end{array}$ & \\
\hline $13-15$ & 108 & 49 & \multirow[t]{2}{*}{$\mathrm{OR}=8.82,95 \% \mathrm{Cl}=1.67-87.01, \mathrm{x}^{2}=7.90, \mathrm{P}=0.003$} \\
\hline $16-17$ & 2 & 8 & \\
\hline \multicolumn{4}{|l|}{ Sex } \\
\hline Male & 75 & $35(31.8)$ & \multirow[t]{2}{*}{$\mathrm{OR}=1.35,95 \% \mathrm{Cl}=0.65-2.76, \mathrm{x}^{2}=0.50, \mathrm{P}=0.48$} \\
\hline Female & 35 & $22(38.6)$ & \\
\hline \multicolumn{4}{|l|}{ Class } \\
\hline Class VII & 40 & $20(33.3)$ & \multirow[t]{3}{*}{$x^{2}=12.28, P=0.002$} \\
\hline Class VIII & 41 & $16(28.07)$ & \\
\hline Class IX & 29 & $21(42.0)$ & \\
\hline \multicolumn{4}{|l|}{ Academic performance } \\
\hline$\geq 75 \%$ & 74 & $37(33.3)$ & \multirow[t]{2}{*}{$\mathrm{OR}=1.11,95 \% \mathrm{Cl}=0.53-2.29, \mathrm{x}^{2}=0.02, \mathrm{P}=0.89$} \\
\hline$<75 \%$ & 36 & $20(35.7)$ & \\
\hline With both parents & 105 & $50(32.3)$ & \multirow[t]{2}{*}{$\mathrm{OR}=6.30,95 \% \mathrm{Cl}=1.47-37.29, \mathrm{x}^{2}=7.13, \mathrm{P}=0.004$} \\
\hline Either of them/guardian & 3 & $9(75.0)$ & \\
\hline
\end{tabular}


while they carried out their study in schools from both urban and rural areas. ${ }^{18}$ In another study of South India, $53 \%$ were boys and $47 \%$ girls, aged between $14-18$ years with mean of 15.6 years. Mostly were 16 years. Nuclear family was in $75 \%$ cases. $^{19}$

There was a study back in 2007 conducted in India based on school-based student health survey. The study reported high parental involvement and significantly association with poor mental health. ${ }^{20}$ The mental health problems in adolescents was seen to be associated significantly with negative life events and parent-adolescent attachment relationship quality. ${ }^{21}$

This aspect was untouched in our study which could be an interesting one. The present study revealed a fact that, nine adolescents had attempted suicide in their lifetime whereas in the study in adolescent students of a public school of Delhi in 2009 also reported suicide among them. ${ }^{22}$ The findings of our study give us an estimate determining the prevalence of adolescents with possibility of depression. The prevalence of depression was $34.0 \%$ which is quite higher than other studies by Umesh et al and Shukla et al ${ }^{18}$ where $6.6 \%$ and $18.7 \%$ of adolescents had depression. The difference might be due to screening by different questionnaire. They had used 6 - Item Kutcher Adolescent Depression Scale (KADS). ${ }^{23}$

The prevalence of depression in the present study was also higher than study done by Trivedi D et $\mathrm{al}^{24}$ and the Delhi study in spite of similar questionnaire, BDI $(22.5 \%$ and 18.4\%). ${ }^{22}$ The South India study ${ }^{19}$ among urban adolescents reported that $37.1 \%$ were mildly depressed, $19.4 \%$ were moderately and $4.3 \%$ severely depressed. The proportion in our study was $24.0 \%, 7.8 \%$ and $2.4 \%$ respectively. Sadness, irritability, self-accusations and crying spells dominated in BDI items over others. A higher proportion of girls $(27 \%)$ reported moderate to severe depression than boys $(21 \%)$ but without significant association like the present one. There was an association between age and depression with increasing depression in older adolescents in previous studies $^{18,19,24}$ that corroborated with our research. In the present study, The mean BDI score of 9.05 was less in our study as compared to reference one (13.7). The results showed a high mean for BDI symptoms like sadness (0.96), self-accusation (0.97), irritability (0.86), expectation of punishment (0.85) and work difficulty (0.83). In the study, more than half respondents did not experience 14 symptoms that were pessimism, sense of failure, dissatisfaction, self-dislike, suicidal thoughts, crying spells, social withdrawal, indecisiveness, body image change, sleep disturbances, anorexia, weight loss, somatic preoccupation and loss of libido. Our study found no gender difference in having depression like some other studies. ${ }^{19,25}$ However in a previously mentioned study from South India depression was present among a significant number of girls $(\mathrm{P}=0.016) .{ }^{24}$ Present study did not found any significant association between depression and type of family, socio-economic class and the findings were similar to other studies. Our study depicted association of the class/standard of the student with level of depression that was contrary to the findings of other studies. Similar to the findings reported in other studies no difference in depression was found with respect to class standards. ${ }^{18,22}$

It had been found that in spite of regular increased number of subjects along with substantial impact, secondary prevention in first level care setting had been suboptimal. Studies have shown that usual care by primary care physicians fails to recognize $30-50 \%$ of depressed patients. ${ }^{26}$ Depression in adolescent age group have profound impact on their socialization, also. The major limitation of the present study was there was lack of information on some important corelates like parental fights and expectation, beating at home and inability to cope up with studies, physical punishment at school, teasing at school etc. that could benefit the research. Depression may be detrimental in future academic performance and also in major life events so strengthening of all sorts of resources in form of infrastructure, manpower must be ensured in the school. Proper counselling under guidance of psychiatrist should be arranged on periodical basis. Teachers must be provided basic training for screening of the mental health problems, so that casualty can be avoided or necessary steps may be implemented in time, thereby reducing both morbidity and mortality.

\section{ACKNOWLEDGEMENTS}

We sincerely thank the medical students for taking part in data collection and making this project successful. We sincerely express our gratitude to the headmaster of the school for helping us in every possible way to make the journey smooth.

\section{REFERENCES}

1. Maternal, newborn, child and adolescent health. World Health Organization. [online] 2017 (cited 2017 Jun 7) Available from: http://www.who.int/maternal_child_adolescent/en.

2. Department of Economic and Social Affairs, World Population Prospects: The 2008 revision. United Nations (UN). [online] 2008 (cited 2017 Jun 7) Available from: www.un.org/esa/population/ publications/wpp2008.

3. UNICEF Data: Monitoring the Situation of Children and Women. [online] 2016 (cited 2017 Jun 7) Available from: https://data. unicef.org/topic/adolescents/adolescent-demographics.

4. Caring for children and adolescents with mental disorders. World Health Organisation Geneva 2003. [online] 2003 (cited 2017 Jun 7) Available from: www.who.int/mental_health/media/en/785. 
5. National Crime Records Bureau. Ministry of Home Affairs, Government of India. [online] (cited 2017 Jun 7) Available from: http://ncrb.nic.in.

6. Bansal V, Goyal S and Srivastava K. Study of Prevalence of depression in adolescent students of a public school in Pune. Indian J Psychiatry 2009, 18: 43-46.

7. Sahoo $S$ and Khess CR. Prevalence of depression, anxiety, and stress among young male adults in India: a dimensional and categorical diagnoses-based study. J Nerv Ment Dis 2010; 198: $901-904$

8. Chhabra GS and Sodhi MK. Factors Contributing to PsychoSocial III-Health in Male Adolescents. Online J Health Allied Scs 2011; 10: 2

9. Salunkhe V, Sutrawe A, Goel R and Jadhav P. Health status of adolescents in Navi Mumbai. Int J Med Clinical Res 2011; 2: 14-19.

10. Kalyani population census 2011. [online] 2011 (cited 2017 Jun 5) Available from: http://www.census2011.co.in/data/town.

11. Statistical Information, Nadia district, West Bengal. [online] 2014 (cited 2017 Jun 5) Available from: http://nadia.gov.in.

12. Office of secondary school inspector, Kalyani municipality. 2015

13. Verma N, Jain M and Roy P. Assessment of magnitude and grades of depression among adolescents in Raipur city, India. Int Res J Medical Sci 2014; 2: 10-13.

14. Global school-based student health survey purpose and methodology. World health organization. [online](cited 2017 Jun 7) Available from: http://www.who.int/chp/gshs/ methodology/en.

15. Becks depression inventory. [online] (cited 2017 Jun 7) Available from: http://www.hr.ucdavis.edu/asap/pdf_files/Beck Depression_Inventory.

16. Becks depression inventory. American psychological association. [online] (cited 2017 Jun 7) Available from: https://www.apa.org/ pi/about/publications/caregivers/practice-settings/assessment/ tools/beck-depression.
17. Ankitha C, Srivastava BK, Eshwar S, Jain V, Kumar R and Swam MR. Overview of socio economic status scales in India. International Journal of Innovative Research in Dental Sciences 2016; 2 : $30-36$.

18. Shukla N K, Shukla M, Ahmad S, Shukla R and Khan Z. A crosssectional study on depression among school going adolescent girls in Barabanki district, Uttar Pradesh, India. Int J Contemp Pediatr 2017;4:178-181.

19. Mohanraj R and Subbaiah KJ. Prevalence of depressive symptoms among urban adolescents in South India. Indian Assoc Child Adolesc Ment Health 2010; 6: 33-43.

20. Hasumi T, Ahsan F, Couper CM, Aguayo JL and Jacobsen KH. Parental involvement and mental well-being of Indian adolescents. Indian Pediatr 2012; 49: 915-918.

21. Bannink R, Broeren S, van de Looij-Jansen PM and Raat H. Associations between parent-adolescent attachment relationship quality, negative life events and mental health. PLoS One 2013; 8: e80812.

22. Bansal V, Goyal S and Srivastava K. Study of prevalence of depression in adolescent students of a public school. Ind Psychiatry J 2009; 18: 43-46.

22. Shelke U, Kunkulol R, Phalke VD, Narwane SP and Patel P. Study of depression among adolescent students of rural Maharashtra and its association with socio-demographic factors: a cross-sectional study. Int J Med Res Health Sci 2015;4:41-45.

24. Trivedi D, Dhakappa N, Ghildiyal P, Deekonda S, Subramaniam S, lyer JS, et al. Depression among adolescent students in South India: How serious is the issue? Indian J Psychiatry 2016; 58: 349-350.

25. Masten WG, Jerome WW, Mosby L, Caldwell-Colbert AT, WilliamsV and Barrios Y. Gender differences in depressive symptoms among Mexican adolescents. Anales de Psicología 2003; 19:91-95.

26. Simon GE and VonKorff M. Recognition, management, and outcomes of depression in primary care. Arch Fam Med 1995; 4: 99-105.

\section{Author's contribution:}

GB - Concept and design of the study, manuscript preparation, statistical analysis, copy editing and critical revision; SB - Data collection, review of literature, helped in preparation of first draft of manuscript.

Orcid ID:

Dr Gandhari:(i) http://orcid.org/0000-0003-3394-1862

Dr Sujata: http://orcid.org/0000-0003-0843-202X

Source of funding: Nil, Conflict of interest: None. 